\title{
Clinical and Histologic Evaluation of Using Block Xenograft Combined With Leukocyte-Platelet Rich Fibrin (L-PRF) Versus Intraoral Autogenous Bone Block Graft With L-PRF in Treating Localized Ridge Defects: A Randomized Clinical Trial
}

\section{Ahmed Y. Gamal, Shahinaz G. Elashiry, Fatma H. Eldemerdash, Omar M. Elnashar}

Department of Oral Medicine, Periodontology, and Oral Diagnosis, Faculty of Dental Medicine, Ain Shams University, Cairo, Egypt.

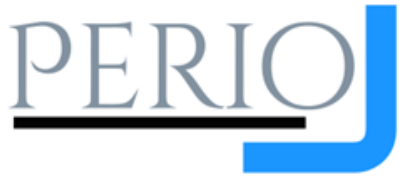

\begin{abstract}
$\underline{\text { Abstract }}$
Background: Augmentation of vertical bone defects remains the corner stone in periodontal tissue engineering. The amount and quality of alveolar bone available in all dimensions affects the success of dental implants for restoration of edentulous areas. Adequate and healthy bone supports the degree of osseointegration which in turn affects the long-term success of oral implants. The primary aim of the study was to histologically evaluate autogenous block grafts versus synthetic block grafts for the treatment of atrophic vertical and horizontal bony defects (Siebert Class III) in the anterior esthetic zone of the mouth. The secondary aim was to clinically and radiographically evaluate the outcomes of the procedure. Methods: This was a randomized controlled clinical study with a statistically determined sample size of 10 patients per group and a total of 20 patients in both groups. Patients with vertical and horizontal bone loss were enrolled from the Department of Oral Medicine, Periodontology, and Oral Diagnosis of Ain Shams University and Misr International University. Bone augmentation procedures were performed using two techniques: autogenous bone block graft and xenograft bone block graft both with leukocyte-platelet rich fibrin (L-PRF). Results: Both autogenous and xenograft blocks in conjunction with L-PRF had a significant effect on vertical bone augmentation in cases of atrophic ridges in the esthetic region. Conclusion: Both autogenous and xenograft bone blocks in conjunction with L-PRF have a significant effect on vertical bone augmentation in cases of atrophic ridges in the esthetic region.
\end{abstract}

Keywords: Localized ridge augmentation; bone block xenograft; leukocyte-platelet rich fibrin (L-PRF); intraoral autogenous bone block graft

\section{Introduction}

The holy grail of periodontal tissue engineering is alveolar bone augmentation in both vertical and horizontal dimensions. The quality and amount of alveolar bone available in all spatial dimensions is critical for successful dental implantation for the repair of edentulous sites. The degree of osseointegration in adequate and healthy bone is critical to the long-term effectiveness of dental implants. ${ }^{1}$
Alveolar bone resorption is a frequent clinical issue that can be caused by a normal or pathologic mechanism such as tooth loss due to extraction, severe periodontal disease or trauma, long-term use of removable appliances, dehiscence and fenestration defects, developmental defects/clefts, congenitally missing teeth, and odontogenic cysts and tumors. Advanced alveolar bone loss $(>7 \mathrm{~mm})$ can affect the esthetics and functionality of removable and fixed partial dentures, as well as optimal implant 
placement in prosthetically driven implantation. ${ }^{2}$

To enable the effective insertion of dental implants in resorbed alveolar bone, a variety of surgical methods and biomaterials have been developed. For this goal, a variety of bone grafting procedures as well as natural and synthetic graft materials have been tried. Despite encouraging outcomes in animal studies, vertical bone augmentation operations have a high chance of failure in human practice. 3

\section{Materials and Methods}

This study was designed as a randomized controlled trial with parallel groups. The study proposal and consent form were reviewed by the Research Ethics Committee of the Ain Shams University Faculty of Oral and Dental Medicine. All participants signed an informed consent that demonstrated the purpose of the study, treatment procedure, and probable risks and benefits of this treatment procedure. Patients also received an explanation of the alternative prosthetic solutions.

\section{Patient Selection}

Twenty patients (12 females and 8 males; aged 28-51 years) were enrolled by the principal investigator starting February 2016 till December 2017 from the Oral Medicine and Periodontology Outpatient Clinic of the Faculty of Oral and Dental Medicine of Ain Shams University and Misr International University. Enrolled were patients with partial edentulism who required vertical and horizontal bone augmentation for esthetic or functional purposes prior to implant placement.

Inclusion criteria for this study were: good general health with no systemic medical conditions, more than 18 years of age, bilateral maxillary anterior partial edentulism, interarch distance greater than $10 \mathrm{~mm}$, at least $2 \mathrm{~mm}$ of keratinized attached gingiva, and horizontal and vertical bone defects greater than $3 \mathrm{~mm}$. The existing residual bone thickness was measured at three different points for horizontal defects; a perpendicular line following the inclination of the residual bone was drawn and three horizontal lines registered the bone width at 5,7 , and $11 \mathrm{~mm}$ from the crest. The average value of the three measurements was subsequently recorded. For vertical defects, the baseline measurements were taken from the viable edge of the alveolar crest up to the limit of the anatomical structures limiting the treatment, which was the base of the nasal floor for the anterior maxilla.

Exclusion criteria included relevant medical conditions, history of head and neck radiation therapy, anticoagulants, antiplatelets, bisphosphonates, or glucocorticoids administered on a daily basis, pregnancy or lactation, smoking more than ten cigarettes per day, heavy bruxism, tooth extraction involving the surgical sites in the previous two months, full mouth plaque and bleeding scores more than 25\% at four sites per tooth, active periodontal disease, chronic diseases affecting bone quality, and psychological disorders.

All patients were randomly assigned to either group A, treated with xenograft bone blocks ${ }^{a}$ with leukocyte-platelet rich fibrin (LPRF), or group B, treated with autogenous bone block grafts with L-PRF.

\section{Presurgical Procedure}

The shape of the alveolar ridge was assessed using periapical radiographs (produced using the paralleling technique with biting blocks), panoramic radiographs, and computed tomographic scans. All patients were prescribed prophylactic antibiotics and a nonsteroidal anti-inflammatory agent consisting of two tablets of amoxicillin/clavulanic acid $(500 \mathrm{mg} / 125$ $\mathrm{mg}$ ) one hour before surgery and one tablet of ketoprofen (50 mg) one hour before surgery. Patients also received a presurgical chlorhexidine digluconate (0.2\%) mouth rinse for two minutes and a sedative premedication of diazepam (20-30 g) 30 minutes before surgery. Articaine 4\% with epinephrine 1:100,000 were used as a local anesthetic.

a Geistlich Bio-Oss $₫$, Wolhusen, Switzerland 


\section{Surgical Phase}

Following administration of local anesthesia, the procedure began with a fullthickness crestal incision within the edentulous ridge's keratinized mucosa. Intrasulcularly, the incision reached one or two distally and mesially neighboring teeth. At the distal and mesial ends of the crestal incision, two vertical releasing incisions were created buccally. To enable wide access for the membrane and ultimate implant placement, the buccal and palatal fullthickness flaps were raised. A continuous releasing periosteal incision was created at the base of the buccal flap, connecting the mesial and distal vertical incisions to produce a totally tension free suture at the conclusion of the procedure.

To obtain the L-PRF, $10 \mathrm{ml}$ of the patient's venous blood was collected in plain vacutainer tubes with no anticoagulants added. The vacutainer tubes were placed in a centrifugal machine at 3,000 revolutions per minute (RPM) for 10 minutes. The blood sample was separated into three layers: a lower red fraction containing red blood cells (RBCs), a middle fraction containing a fibrin clot, and an upper straw colored cellular plasma. The upper layer was removed to allow for collection of the middle fraction containing the fibrin clot. The extracted LPRF was placed over the bone block graft.

According to their randomly assigned group, each patient received either a xenogenous bone graft or an autogenous bone graft harvested from the mental region using surgical burs. The bone block graft was then placed at the site of the bone defect and fixed with screws.

The flaps were gently advanced buccally to attain primary closure. Horizontal mattress sutures ${ }^{b}$ with $U$ stitches were applied first to ensure proper flap apposition with the connective tissue surfaces facing each other. Subsequently, interrupted sutures were used between the horizontal mattress to approximate the vertical incisions.
Figure 1.

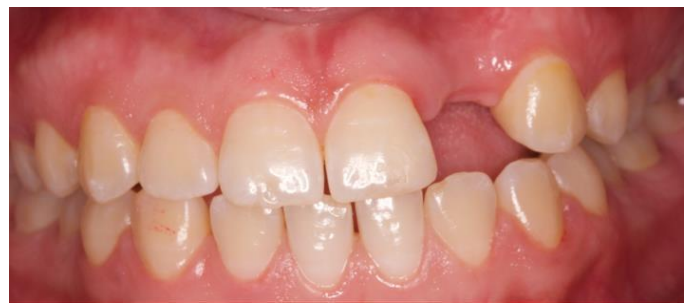

Preoperative photograph showing a missing upper left lateral incisor with a bone defect

Figure 2.

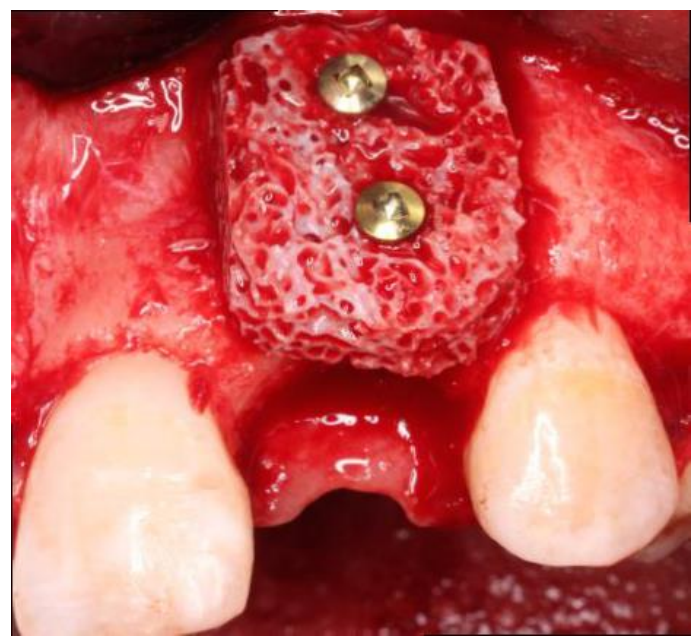

Clinical picture showing xenograft bone block fixation using non-self-tapping screws

\section{Postsurgical}

All patients underwent antibiotic prophylactic treatment consisting of one tablet of amoxicillin/clavulanic acid (500 $\mathrm{mg} / 125 \mathrm{mg}$ ) three times a day for one week, and one tablet of ketoprofen (50 $\mathrm{mg}$ ) was prescribed three times a day for four days. Patients were also instructed to rinse twice daily for 7 to 10 days with chlorhexidine digluconate (0.2\%). Postoperative instructions were to use a cold pack, eat a soft food diet, avoid hot food and drinks, avoid demanding physical work or exercise, and refrain from wearing a prosthesis on the treated area for two weeks. Sutures were removed 14 days after surgery.

After nine months of submerged healing, all patients underwent a second surgery in order to obtain a bone sample with a $4 \mathrm{~mm}$ trephine bur and to place the implants. Cylindric screw-shaped implants ${ }^{c}$ were inserted in the vertically augmented bone. All implants had a TiUnite rough surface, a $3.75 \mathrm{~mm}$ diameter conical connection, and a length of 8.5 to $13 \mathrm{~mm}$ depending on the anatomic limitations. Bone quality (according to the Lekholm and Zarb

b GORE-TEX® Suture (CV-5), W.L. Gore \& Associates, Inc., Newark, DE, USA

c In-Kone ${ }^{\circledR}$, Brignais, France 
classification) and insertion torque were assessed for each implant. Healing abutments were placed after five months and the implants were tested for stability.

\section{Figure 3.}

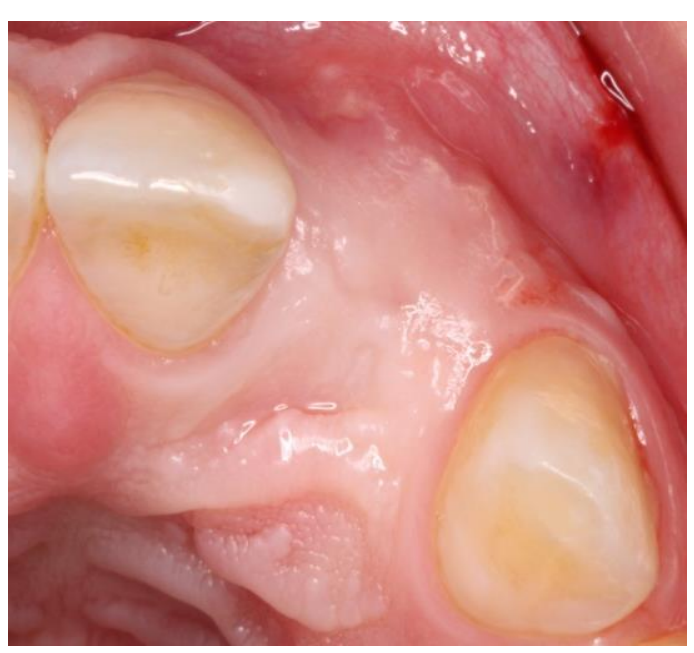

Clinical picture showing follow up of bone augmentation site using xenograft bone block after nine months (occlusal view)

\section{Histologic Analysis}

The bone tissues were immediately stored in $10 \%$ buffered formalin and processed to obtain thin ground sections. The specimens were dehydrated in an ascending series of alcohol rinses and embedded in a glycol methacrylate resin. After polymerization, the specimens were sectioned longitudinally ground down to about $30 \mathrm{pm}$. Three slides were obtained which were stained with basic fuchsin and toluidine blue.

Histomorphometric analysis of the bone tissue specimen was carried out using a light microscope connected to a high-resolution video camera ${ }^{\mathrm{d}}$ and interfaced to a monitor and personal computer. This optical system was associated with a digitizing pade and a histometry software package with image capturing capabilities. ${ }^{f}$

\section{$\underline{\text { Results }}$}

\section{Demographic Data}

A statistical analysis of demographic data for group A revealed an age range of 28-51 years with a gender distribution of 8 males and 12 females Tooth types included 4 (25\%) upper lateral incisors and 12 (75\%) upper central incisors. Demographic data for group B showed an age range of 29-43 years with a gender distribution of 7 males and 14 females. Tooth types included 4 (20\%) upper lateral incisors and 16 (80\%) upper central incisors. A demographic data comparison between groups and subgroups did not reveal any statistically significant differences.

\section{Clinical Results}

Clinical results are summarized in Table 2.

\section{A. Comparison Within the Same Group}

The mean value increased at re-entry in both groups and the paired t-test demonstrated that the difference between baseline and reentry was statistically significant in both groups $(\mathrm{P}=0)$.

\section{B. Comparison Between Groups}

At baseline, there was no statistically significant difference between both groups $(\mathrm{P}=0.682)$. At re-entry, the same mean value was recorded for both groups with no significant difference $(\mathrm{P}=1)$.

\section{Clinical Gain in Alveolar Ridge After Treatment}

A higher mean value was recorded for the autogenous bone blocks with L-PRF group $(3.55 \pm 0.93 \mathrm{~mm})$ in comparison to the xenograft bone blocks with L-PRF group $(3.20 \pm 0.75 \mathrm{~mm})$. The independent t-test did not demonstrate a statistically significant difference between both groups $(\mathrm{P}=0.367)$.

\section{Histomorphogenic Analysis of Vertical Augmentation}

\section{A. New Vital Bone (NVB)\%}

A higher mean value was recorded for the autogenous bone blocks with L-PRF group $(58.91 \pm 1.68 \mathrm{~mm})$ compared to the xenograft bone blocks with L-PRF group (48.69 \pm 0.85 $\mathrm{mm}$ ). The independent t-test revealed a statistically significant difference between both groups $(\mathrm{P}=0)$ (Table 3$)$.

\section{B. Residual Graft (RG)\%}

A higher mean value was recorded for the xenograft bone blocks with L-PRF group

d JVC KY-F55BU, 3-CCD, Yokohama, Japan

e MATRIX VISION GmbH, Oppenweiler, Germany

f Image-Pro Plus@ 4.5, Media Cybernetics, Inc., Rockville, MD, USA 
$(38.43 \pm 0.97 \mathrm{~mm})$ in comparison to the autogenous bone blocks with L-PRF group $(26.47 \pm 1.46 \mathrm{~mm})$. The independent $\mathrm{t}$-test demonstrated a statistically significant difference between both groups $(\mathrm{P}=\mathrm{O})$ (Table 4).

Table 1. Clinical measurements (millimeters) of the alveolar ridges before and after bone augmentation

\begin{tabular}{|c|c|c|c|c|c|c|}
\hline & & & Baseline & $\begin{array}{l}\text { Re- } \\
\text { Entry }\end{array}$ & $\mathbf{t}$ & $\begin{array}{c}\text { P } \\
\text { (Within } \\
\text { Group) }\end{array}$ \\
\hline \multirow{9}{*}{$\begin{array}{l}\text { Xenograft Bone } \\
\text { Blocks with L-PRF }\end{array}$} & \multicolumn{2}{|l|}{ Mean } & 3.60 & 6.80 & \multirow{9}{*}{13.44} & \multirow{9}{*}{$0.00^{*}$} \\
\hline & \multirow{2}{*}{$\begin{array}{c}95 \% \\
\text { Confidence } \\
\text { Interval for Mean }\end{array}$} & $\begin{array}{l}\text { Lower } \\
\text { bound }\end{array}$ & 2.97 & 6.14 & & \\
\hline & & $\begin{array}{l}\text { Upper } \\
\text { bound }\end{array}$ & 4.23 & $7 \cdot 46$ & & \\
\hline & \multicolumn{2}{|l|}{ Median } & 3.75 & 7.00 & & \\
\hline & \multicolumn{2}{|c|}{ Standard Deviation } & .88 & .92 & & \\
\hline & \multicolumn{2}{|c|}{ Minimum } & 2.00 & 5.00 & & \\
\hline & \multicolumn{2}{|c|}{ Maximum } & 5.00 & 8.00 & & \\
\hline & \multicolumn{2}{|l|}{ Range } & 3.00 & 3.00 & & \\
\hline & \multicolumn{2}{|c|}{ Interquartile Range } & 1.13 & 1.25 & & \\
\hline \multirow{3}{*}{$\begin{array}{l}\text { Autogenous Bone } \\
\text { Blocks with L-PRF }\end{array}$} & \multicolumn{2}{|l|}{ Mean } & 3.45 & 6.80 & \multirow{3}{*}{11.59} & \multirow{3}{*}{$0.00^{*}$} \\
\hline & \multirow{2}{*}{$\begin{array}{c}95 \% \\
\text { Confidence } \\
\text { Interval for Mean }\end{array}$} & $\begin{array}{l}\text { Lower } \\
\text { Bound }\end{array}$ & 2.93 & 6.14 & & \\
\hline & & $\begin{array}{l}\text { Upper } \\
\text { Bound }\end{array}$ & 3.97 & $7 \cdot 46$ & & \\
\hline & \multicolumn{2}{|l|}{ Median } & 3.50 & 7.00 & & \\
\hline & \multicolumn{2}{|c|}{ Standard Deviation } & .72 & .92 & & \\
\hline & \multicolumn{2}{|c|}{ Minimum } & 2.00 & 5.00 & & \\
\hline & \multicolumn{2}{|c|}{ Maximum } & 4.50 & 8.00 & & \\
\hline & \multicolumn{2}{|l|}{ Range } & 2.50 & 3.00 & & \\
\hline & \multicolumn{2}{|c|}{ Interquartile Range } & 1.00 & 1.25 & & \\
\hline \multicolumn{3}{|c|}{$\mathbf{t}$} & 0.417 & o & & \\
\hline \multicolumn{3}{|c|}{ P (Between Groups) } & $.682 \mathrm{~ns}$ & $1 \mathrm{~ns}$ & & \\
\hline
\end{tabular}

Significance level: P $\leq 0.05 ;{ }^{*}$ : significant; ns: non-significant

Table 2. Gain in clinical measurements (millimeters) after treatment in both groups (independent t-test)

\begin{tabular}{|c|c|c|c|}
\hline & & $\begin{array}{l}\text { Xenograft Bone } \\
\text { Blocks with } \\
\text { L-PRF }\end{array}$ & $\begin{array}{l}\text { Autogenous Bone } \\
\text { Blocks with } \\
\text { L-PRF }\end{array}$ \\
\hline \multicolumn{2}{|l|}{ Mean } & 3.20 & 3.55 \\
\hline \multirow{2}{*}{$\begin{array}{l}95 \% \text { Confidence Interval } \\
\text { for Mean }\end{array}$} & $\begin{array}{l}\text { Lower } \\
\text { Bound }\end{array}$ & 2.66 & 2.89 \\
\hline & $\begin{array}{l}\text { Upper } \\
\text { Bound }\end{array}$ & 3.74 & 4.21 \\
\hline \multicolumn{2}{|l|}{ Median } & 3.25 & 3.75 \\
\hline \multicolumn{2}{|c|}{ Standard Deviation } & .75 & .93 \\
\hline \multicolumn{2}{|c|}{ Minimum } & 2.00 & 2.00 \\
\hline \multicolumn{2}{|l|}{ Maximum } & 4.00 & 5.00 \\
\hline \multicolumn{2}{|c|}{$\begin{array}{c}\text { Range } \\
\end{array}$} & 2.00 & 3.00 \\
\hline \multicolumn{2}{|c|}{ Interquartile Range } & 1.25 & 1.25 \\
\hline \multicolumn{2}{|c|}{$\mathbf{t}$} & \multicolumn{2}{|c|}{0.927} \\
\hline \multicolumn{2}{|c|}{ P (Between Groups) } & \multicolumn{2}{|c|}{$.367 \mathrm{~ns}$} \\
\hline
\end{tabular}

Significance level: $\mathrm{P} \leq 0.05$; *: significant; ns: non-significant 
$(3.74 \pm 0.65 \mathrm{~mm})$ in comparison to the xenograft bone blocks with L-PRF group $(2.91 \pm 0.54 \mathrm{~mm})$, and the independent t-test revealed a statistically significant difference between both groups $(\mathrm{P}=0.006)$ (Table 7).

Table 5. Histomorphogenic analysis (CT\%) after treatment in both groups (independent t-test)

\begin{tabular}{|c|c|c|c|}
\hline \multicolumn{2}{|l|}{ СТ\% } & $\begin{array}{l}\text { Xenograft Bone } \\
\text { Blocks with } \\
\text { L-PRF }\end{array}$ & $\begin{array}{c}\text { Autogenous Bone } \\
\text { Blocks with } \\
\text { L-PRF } \\
\end{array}$ \\
\hline \multicolumn{2}{|l|}{ Mean } & 12.94 & 14.62 \\
\hline \multirow{2}{*}{$\begin{array}{l}95 \% \text { Confidence Interval } \\
\text { for Mean }\end{array}$} & $\begin{array}{l}\text { Lower } \\
\text { Bound }\end{array}$ & 12.22 & 13.78 \\
\hline & $\begin{array}{l}\text { Upper } \\
\text { Bound }\end{array}$ & 13.66 & 15.46 \\
\hline \multicolumn{2}{|c|}{ Median } & $13 \cdot 35$ & 14.75 \\
\hline \multicolumn{2}{|c|}{ Standard Deviation } & 1.00 & 1.18 \\
\hline \multicolumn{2}{|c|}{ Minimum } & 11.30 & 12.40 \\
\hline \multicolumn{2}{|l|}{ Maximum } & 14.20 & 16.00 \\
\hline \multicolumn{2}{|c|}{ Range } & 2.90 & 3.60 \\
\hline \multicolumn{2}{|c|}{ Interquartile Range } & 1.73 & 1.80 \\
\hline \multicolumn{2}{|c|}{ t } & \multicolumn{2}{|c|}{-3.434} \\
\hline \multicolumn{2}{|c|}{ P (Between Groups) } & \multicolumn{2}{|c|}{$0.003^{*}$} \\
\hline
\end{tabular}

Significance level: $\mathrm{P} \leq 0.05$; $^{*}$ : significant

Table 6. Radiographic CBCT measurements (millimeters) of the alveolar ridges before and after bone augmentation

\begin{tabular}{|c|c|c|c|c|c|c|}
\hline & & & Preoperative & Postoperative & $\mathbf{t}$ & $\begin{array}{c}\mathbf{P} \\
\text { (Within } \\
\text { Groups) }\end{array}$ \\
\hline & Mea & & 3.95 & 6.86 & & \\
\hline & $\begin{array}{c}95 \% \\
\text { Confidence }\end{array}$ & $\begin{array}{l}\text { Lower } \\
\text { Bound }\end{array}$ & $3 \cdot 36$ & 6.16 & & \\
\hline Xenograft Bone & $\begin{array}{l}\text { Interval for } \\
\text { Mean }\end{array}$ & $\begin{array}{l}\text { Upper } \\
\text { Bound }\end{array}$ & 4.55 & $7 \cdot 56$ & & \\
\hline Blocks with L- & Medi & & 3.72 & 6.76 & 17.11 & $0.00^{*}$ \\
\hline PRF & Standard D & iation & .83 & .98 & & \\
\hline & Minim & & 2.92 & 5.49 & & \\
\hline & Maxin & & 5.40 & 8.51 & & \\
\hline & Ran & & 2.48 & 3.02 & & \\
\hline & Interquarti & Range & 1.48 & 1.67 & & \\
\hline & Mea & & 3.64 & $7 \cdot 38$ & & \\
\hline $\begin{array}{l}\text { Autogenous } \\
\text { Bone Blocks }\end{array}$ & $\begin{array}{c}95 \% \\
\text { Confidence }\end{array}$ & $\begin{array}{l}\text { Lower } \\
\text { Bound }\end{array}$ & 3.07 & 6.87 & 18.18 & $0.00^{*}$ \\
\hline with L-PRF & $\begin{array}{l}\text { Interval for } \\
\text { Mean }\end{array}$ & $\begin{array}{l}\text { Upper } \\
\text { Bound }\end{array}$ & 4.21 & 7.89 & & \\
\hline & Medi & & 3.48 & $7 \cdot 36$ & & \\
\hline & Standard D & iation & .79 & .71 & & \\
\hline & Minim & & 2.40 & 6.49 & & \\
\hline & Maxin & & 4.83 & 8.69 & & \\
\hline & $\operatorname{Ran}$ & & 2.43 & 2.20 & & \\
\hline & Interquarti & Range & 1.35 & 1.30 & & \\
\hline & $\mathrm{t}$ & & .861 & -1.343 & & \\
\hline P (Bety & en Groups) & & $0.40 \mathrm{~ns}$ & $0.198 \mathrm{~ns}$ & & \\
\hline
\end{tabular}

Significance level: P $\leq 0.05$; * significant; ns: non-significant

\section{Discussion}

The problem of bone loss that occurs following tooth extraction is that it can affect esthetics as well as further prosthetic solutions and future implant placement in the defect site._Augmentation of vertical bone defects remains the corner stone in periodontal tissue engineering. The amount and quality of alveolar bone available in all dimensions affects the success of dental implants for restoration of edentulous areas. Adequate and healthy bone supports the 
degree of osseointegration which in turn affects the long-term success of oral implants. ${ }^{14}$

Physiologic and pathologic bone loss are considered a common clinical problem. Multiple causes may lead to this problem including periodontal disease, tooth loss, trauma, or using removable prostheses for extended periods. Excessive bone loss (greater than $7 \mathrm{~mm}$ ) may lead to fixed prosthodontics with poor esthetics and function.15 Many biomaterials and surgical techniques were introduced and developed to make oral implantology more successful in cases of an atrophic alveolar process. Multiple bone grafts were tested for this purpose and procedures of bone augmentation faced high rates of failure in clinical practice despite the animal trials that showed promising results. ${ }^{16}$

The size of the vertical bone defect and the buccolingual width are factors that can affect the success of augmentation procedures. 14 The width of the defect's base is also put into consideration as wider alveolar ridges have a greater potency for bone regeneration compared to narrow sites. 4 The surgical procedures for both groups aimed to ensure adequate outcome of the augmentation process. Factors such as flap design (advancement flap) and recipient site preparation were considered in the present study in order to provide proper vascularization and tension free closure of the flap. Stabilization of the block grafts in place of the defect was also accomplished by using screws to maintain the grafts in position.

Table 7. Gain in radiographic (CBCT) measurements (millimeters) after treatment in both groups (independent t-test)

\begin{tabular}{|c|c|c|c|}
\hline & & $\begin{array}{c}\text { Xenograft Bone } \\
\text { Blocks with } \\
\text { L-PRF }\end{array}$ & $\begin{array}{c}\text { Autogenous Bone Blocks } \\
\text { with L-PRF }\end{array}$ \\
\hline \multicolumn{2}{|l|}{ Mean } & 2.91 & 3.74 \\
\hline \multirow{2}{*}{$\begin{array}{l}95 \% \text { Confidence } \\
\text { Interval for Mean }\end{array}$} & $\begin{array}{l}\text { Lower } \\
\text { Bound }\end{array}$ & 2.53 & 3.27 \\
\hline & $\begin{array}{l}\text { Upper } \\
\text { Bound }\end{array}$ & 3.29 & 4.20 \\
\hline \multicolumn{2}{|c|}{ Median } & 2.81 & 3.65 \\
\hline \multicolumn{2}{|c|}{ Standard Deviation } & .54 & .65 \\
\hline \multicolumn{2}{|c|}{ Minimum } & 2.11 & 2.68 \\
\hline \multicolumn{2}{|c|}{ Maximum } & 3.68 & 4.61 \\
\hline \multicolumn{2}{|c|}{ Range } & 1.57 & 1.93 \\
\hline \multicolumn{2}{|c|}{ Interquartile Range } & .98 & 1.23 \\
\hline \multicolumn{2}{|c|}{$\mathbf{t}$} & \multicolumn{2}{|r|}{3.109} \\
\hline \multicolumn{2}{|c|}{ P (Between Groups) } & \multicolumn{2}{|c|}{$0.006^{*}$} \\
\hline
\end{tabular}

Significance level: $\mathrm{P} \leq 0.05$; * significant

Two types of block grafts were used in the present study (autogenous bone blocks and xenograft bone blocks). Both grafts were documented in dental literature to have a positive effect on the augmentation of vertical bone defects. ${ }^{17}$ Autogenous bone grafts were harvested from the mental region in order to provide thicker blocks that cannot be retrieved from other intraoral sites. Both block grafts were mixed with L-PRF, which was prepared according to Choukron et al.'s recommendations with immediate handling of the blood samples and centrifugation without adding anticoagulants or bovine thrombin. ${ }^{18}$
The results of the postoperative clinical vertical bone height in this study demonstrated a statistically significant increase in both studied groups in comparison to the base line preoperative condition. These results were in accordance with other studies that have shown a positive impact for both graft types on vertical bone augmentation outcome. ${ }^{17}$

The results of the mean clinical bone gain were higher in the autogenous bone graft group with L-PRF $(3.55 \pm 0.93 \mathrm{~mm})$ in comparison to the xenograft augmented group with L-PRF $(3.20 \pm 0.75 \mathrm{~mm})$. There 
was no statistical difference however, between both groups. These results were in agreement with other studies, which considered the autogenous bone graft a gold standard for vertical bone defect augmentation due to its osteogenic potential.5,6 It has the capacity to repair bone via osteogenesis, osteoinduction, and osteoconduction. Screwable xenogenous bone was described as a useful scaffold for ridge augmentation procedures. Xenogenous blocks were found to have osteoconductive properties and osseous organization on a level equivalent to autologous grafts. 7

The addition of L-PRF enhances the effect of block grafts by promoting soft tissue healing and bone regeneration. ${ }^{13}$ Platelet concentrate technologies include many factors that may sometimes be more important than platelet growth factors, including the fibrin matrix and leukocytes. Platelets play a crucial role not only in hemostasis, but also in the wound healing process. ${ }^{8}$ They also release a variety of cytokines and growth factors, while leukocytes were described as having a very strong impact on healing due to their antimicrobial effects and their regulation of immune reactions. ${ }^{6-9}$

Further histomorphogenic analysis to assess the quality of the formed bone revealed a higher mean value of NVB\% in the autogenous blocks with L-PRF group (58.91 $1.68 \%)$ in comparison to the xenograft bone blocks with L-PRF group (48.69 $\pm 0.85 \%)$. The independent t-test revealed a statistically significant difference between both groups, which could be attributed to the superior osteoinductive and osteoconductive properties of autogenous bone blocks. ${ }^{10}$

A higher statistically significant mean value of CT\% was recorded in the autogenous bone blocks with L-PRF group $(14.62 \pm 1.18 \%)$ compared to the xenograft blocks with L-PRF group (12.94 $\pm 1 \%$ ) with a $\mathrm{P}$ value of 0.003 . These results were contradictory to other findings which explained that xenogenous bone grafts were filled with large portions of connective tissue with only moderate amounts of new bone formed at the base of the graft. ${ }^{19}$ A low connective tissue percentage in the xenograft block group can be attributed to the microscopic structure of the xenograft that has an interconnecting pore system which serves as a scaffold for the migration of osteogenic cells; this microscopic structure is similar to that of natural cancellous bone. ${ }^{11,12}$ In addition, the growth factors and leukocytes that mediate the immune response found in L-PRF can enhance the outcome of augmentation. ${ }^{13}$

The study concluded that both autogenous and xenograft bone blocks in conjunction with L-PRF have a significant effect on vertical bone augmentation in cases of atrophic ridges in the esthetic region.

\section{References}

1. Fontana F, Santoro F, Maiorana C, Iezzi G, Piattelli A, Simion M. Clinical and histologic evaluation of allogenic bone matrix versus autogenous bone chips associated with titanium-reinforced ePTFE membrane for vertical ridge augmentation: a prospective pilot study. Int J Oral Maxillofac Implants. 2008 Nov-Dec; 23(6):1003-12.

2. Duvina M, Barbato L, Brancato L, Rose GD, Amunni F, Tonelli P. Biochemical markers as predictors of bone remodelling in dental disorders: a narrative description of literature. Clin Cases Miner Bone Metab. 2012; 9(2):100-106.

3. Sacco AG, Chepeha DB. Current status of transport-disc-distraction osteogenesis for mandibular reconstruction. Lancet Oncol. 2007 Apr; 8(4):323-330. https://doi.org/10.1016/S14702045(07)70102-X

4. Iasella, JM, Greenwell H, Miller RL, et al. Ridge preservation with freezedried bone allograft and a collagen membrane compared to extraction alone for implant site development: a clinical and histologic study in humans. $J$ Periodontol. $2003 \mathrm{Jul}$; 74(7):990-999.

https://doi.org/10.1902/jop.2003.74 .7 .990 
5. Dohan Ehrenfest DM, Rasmusson L, Albrektsson T. Classification of platelet concentrates: from pure platelet-rich plasma (P-PRP) to leucocyte- and platelet-rich fibrin (LPRF). Trends Biotechnol. 2009 Mar; 27(3):158-167.

https://doi.org/10.1016/j.tibtech.20 08.11.009

6. Whitman DH, Berry RL, Green DM. Platelet gel: an autologous alternative to fibrin glue with applications in oral and maxillofacial surgery. $J$ Oral Maxillofac Surg. 1997 Nov; 55(11):1294-1299.

https://doi.org/10.1016/s02782391(97)90187-7

7. Marx RE, Carlson ER, Eichstaedt RM, Schimmele SR, Strauss JE, Georgeff KR. Platelet-rich plasma: Growth factor enhancement for bone grafts. Oral Surg Oral Med Oral Pathol Oral Radiol Endod. 1998 Jun; 85(6):638646. https://doi.org/10.1016/s10792104(98)90029-4

8. Dohan Ehrenfest DM, Bielecki T, Del Corso M, Inchingolo F, Sammartino G. Shedding light in the controversial terminology for platelet-rich products: platelet-rich plasma (PRP), plateletrich fibrin (PRF), platelet-leukocyte gel (PLG), preparation rich in growth factors (PRGF), classification and commercialism. $J$ Biomed Mater Res A. 2010 Dec; 95(4):1280-1282. https://doi.org/10.1002/jbm.a.32894

9. Bielecki T, Gazdzik TS, Szczepanski T. Re: "The effects of local platelet rich plasma delivery on diabetic fracture healing". What do we use: Plateletrich plasma or platelet-rich gel? Bone. 2006 Dec; 39(6):1388; author reply 1389.

https://doi.org/10.1016/j.bone.2006 .06 .015

10. Everts PA, Overdevest EP, Jakimowicz JJ, et al. The use of autologous platelet-leukocyte gels to enhance the healing process in surgery, a review. Surg Endosc. 2007; 21:2063-2068. https://doi.org/10.1007/s00464007-9293-x

11. Bielecki TM, Gazdzik TS, Arendt J, Szczepanski T, Król W, Wielkoszynski T. Antibacterial effect of autologous platelet gel enriched with growth factors and other active substances: an in vitro study. $J$ Bone Joint Surg Br. 2007 Mar; 89(3):417-420. https://doi.org/10.1302/0301620X.89B3.18491

12. Cieslik-Bielecka A, Bielecki T, Gazdzik TS, Arendt J, Król W, Szczepanski T. Autologous platelets and leukocytes can improve healing of infected high-energy soft tissue injury. Transfus Apher Sci. 2009 Aug; 41(1):9-12. https://doi.org/10.1016/j.transci.20 09.05 .006

13. Bielecki T, Gazdzik TS, Szczepanski T. Benefit of percutaneous injection of autologous platelet-leukocyte-rich gel in patients with delayed union and nonunion. Eur Surg Res. 2008; 40(3):289-296.

https://doi.org/10.1159/000114967

14. Everts PA, Devilee RJ, Brown Mahoney $\mathrm{C}$, et al. Exogenous application of platelet-leukocyte gel during open subacromial decompression contributes to improved patient outcome. Eur Surg Res. 2008; 40(2):203-210. https://doi.org/10.1159/000110862

15. Choukroun J, Adda F, Schoeffer C, Vervelle A. PRF: an opportunity in perio-implantology. Implantodontie. 2000; 42:55-62.

16. Gassling VL, Açil Y, Springer IN, Hubert N, Wiltfang J. Platelet-rich plasma and platelet-rich fibrin in human cell culture. Oral Surg Oral Med Oral Pathol Oral Radiol Endod. 2009 Jul; 108(1):48-55. https://doi.org/10.1016/j.tripleo.200 9.02.007

17. Wychowanski P, Woliński J, Morawiec T, et al. Preliminary 
Clinical Data and the Comparison of the Safety and Efficacy of Autogenous Bone Grafts Versus Xenograft Implantations in Vertical Bone Deficiencies Before Dental Implant Installation. Transplant Proc. 2020 Sep; 52(7):2248-2251. https://doi.org/10.1016/j.transproce ed.2020.02.099

18. Choukroun J, Diss A, Simonpieri A, et al. Platelet-rich fibrin (PRF): a second-generation platelet concentrate. Part IV: clinical effects on tissue healing. Oral Surg Oral Med Oral Pathol Oral Radiol Endod. 2006 Mar; 101(3):e56-60. https://doi.org/10.1016/j.tripleo.200 5.07.011

19. Nazirkar G, Singh S, Dole V, Nikam A. Effortless effort in bone regeneration: a review. J Int Oral Health. 2014 Jun; 6(3):120-124.

Conflicts of interest: The authors declared no conflicts of interest related to this work.

\section{Corresponding author:}

Dr. Omar Mohamed Farouk Elnashar Department of Oral Medicine,

Periodontology, and Oral Diagnosis

Faculty of Dental Medicine

Ain Shams University

Cairo, Egypt

E-mail: omarnashar@hotmail.com

Phone: +20 1226212222

This is an open access article distributed under the Creative Commons AttributionNoncommercial-NoDerivatives $\quad 4.0$ International (CC BY-NC-ND 4.0) License. 